\title{
BMJ Open Self-reported secondhand smoke exposure following the adoption of a national smoke-free policy in Poland: analysis of serial, cross-sectional, representative surveys, 2009-2019
}

\author{
Mateusz Jankowski (D) , ${ }^{1,2}$ Vaughan Rees, ${ }^{2}$ Wojciech Stefan Zgliczyński (D) , \\ Dorota Kaleta, ${ }^{3}$ Mariusz Gujski (iD , ${ }^{4}$ Jarosław Pinkas ${ }^{1}$
}

To cite: Jankowski M, Rees V, Zgliczyński WS, et al. Selfreported secondhand smoke exposure following the adoption of a national smoke-free policy in Poland: analysis of serial, cross-sectional, representative surveys, 2009-2019. BMJ Open 2020;10:e039918. doi:10.1136/ bmjopen-2020-039918

- Prepublication history for this paper is available online. To view these files, please visit the journal online (http://dx.doi. org/10.1136/bmjopen-2020039918).

Received 29 April 2020

Revised 06 August 2020

Accepted 01 September 2020

Check for updates

(c) Author(s) (or their employer(s)) 2020. Re-use permitted under CC BY-NC. No commercial re-use. See rights and permissions. Published by BMJ.

For numbered affiliations see end of article.

Correspondence to Dr Mateusz Jankowski; mjankowski@cmkp.edu.pl

\section{ABSTRACT}

Objective We assessed changes in secondhand smoke (SHS) exposure in workplaces and public venues in Poland over a 9-year period following the adoption of a smokefree policy in Poland in 2010.

Design Six waves of cross-sectional surveys were carried out between 2009 and 2019.

Participants A nationally representative sample of adult Polish residents (age 15 years and older) was surveyed. Survey respondents self-reported SHS exposure in the workplace and 12 different public venues. Data were analysed separately for samples consisting of (1) all respondents and (2) non-smokers only.

SHS exposure was defined based on self-report, which may invoke error such as demand bias or recall bias and study protocol do not include participation of paediatric populations that are key limitations of this study.

Results Within a year of adopting the smoke-free policy in 2010, the proportion of non-smokers exposed to SHS in Polish workplaces decreased by more than half (from $19.2 \%$ in 2009 to $9.5 \%$ in 2011). Over 10 years, a substantial reduction in SHS exposure was observed in all public venues. The highest decrease in SHS exposure was observed in transport services (decreased from $45.7 \%$ to $11.7 \%$ among all respondents and from $44.2 \%$ to $11.7 \%$ among non-smokers) and in bars/pubs (SHS exposure decreased from $45.0 \%$ to $7.0 \%$ among all respondents and from $39.4 \%$ to $7.0 \%$ among non-smokers).

Conclusions This study demonstrates the substantial success of a national smoke-free law. Nevertheless, smoke-free laws must continue to be refined in terms of their legal boundaries as well as implementation strategies to eliminate disparities in SHS exposure in certain types of venues.

\section{INTRODUCTION}

Exposure to secondhand smoke (SHS) is associated with increased prevalence of tobaccorelated diseases and premature death among non-smoking adults and children. ${ }^{1-3}$ Article 8 of WHO's Framework Convention on Tobacco Control calls for protection from

\section{Strengths and limitations of this study}

- This is the most comprehensive study on secondhand smoke (SHS) exposure in Poland presenting findings from six waves (2009-2011-2013-20152017-2019) of cross-sectional surveys carried out in a nationally representative sample of adult Polish residents

- Findings from this study point out significant implications for ongoing policy implementation in Poland and our results may be useful for policymakers from the Central and Eastern European region.

- SHS exposure was defined based on self-report, which may invoke error such as demand bias or recall bias. Ideally, SHS exposure should be biochemically verified using biomarkers of exposures such as cotinine.

- All six cross-sectional surveys assessed SHS exposure in individuals aged 15 years of age and older, so rates of SHS exposure among paediatric populations may be different from those reported here.

exposure to SHS with an obligation to all convention parties to implement comprehensive smoke-free policies. ${ }^{4}$ Moreover, in 2009, the European Commission called on European Union (EU) countries to adopt and implement comprehensive laws to fully protect their citizens from SHS exposure. ${ }^{5}$ According to European Commission data, 17 of 28 EU countries currently have comprehensive smoke-free laws in place. ${ }^{5}$ Nonetheless, in 2017, 20\% of EU citizens reported being exposed to SHS when visiting bars. ${ }^{6}$ Globally, according to WHO estimate, only $22 \%$ of the world's population is protected by comprehensive national smoke-free laws (including smoking prohibition in all workplaces and indoor public places). ${ }^{7}$

Poland is a country with a heavy burden of tobacco-related diseases. ${ }^{89}$ According to the 
Table 1 Tobacco control act in Poland-key regulations relating to protection against SHS exposure

Title of the document Entry into force Main assumptions

\section{Act of 9 November 1995 on protection of public health against the effects of using tobacco and tobacco products ${ }^{12}$}

1 May to 1996

It is forbidden to smoke on the premises of: (1) healthcare establishments; (2) education system organisational units and (3) enclosed workplaces and other premises designated for public use.

Act of 8 April 2010 amending the act on protection of public health against the effects of using tobacco and tobacco products $^{12}$

15 November to 2010 It is forbidden to smoke on the premises of: (1) healthcare establishments, and other, where healthcare services are provided; (2) educational institutions; (3) higher education institutions; (4) work places; (5) public cultural and recreational establishments; (6) food and entertainment establishments; (7) in passenger public transportation means, and establishments servicing travellers; (8) public transportation stops; (9) sport establishments; (10) public playgrounds for children; (11) and other premises designated for public use.

Act of 22 July 2016 amending the act on $\quad 8$ September to 2016
protection of public health against the $\begin{aligned} & \text { The } 2010 \text { prohibition was extended to include electronic } \\ & \text { cigarettes and innovative tobacco products. } \\ & \text { effects of using tobacco and tobacco } \\ & \text { products }^{12}\end{aligned}$

SHS, secondhand smoke.

data published by the Global Burden of Disease Collaborative Network, in 2005, the death rate from tobacco smoking in Poland was 132.9 per 100000 which is higher compared with neighbouring countries: Germany (76.6 per 100 000), Czech Republic (117.2 per 100 000), Slovakia (119.2 per 100 000) and Lithuania (115.5 per $100000) .{ }^{10}$ In 2019, the death rate from smoking was also higher in Poland (108.9 deaths per 100 000) compared with the other countries from the region, respectively: 74 per 100000 in Germany, 98 per 100000 in the Czech Republic, 90.2 per 100000 in Slovakia and 101 per 100000 in Lithuania, ${ }^{10}$ underscoring an important disparity between Poland and other eastern European countries in tobacco-related outcomes. In 1995, Poland became the first former communist country in the Central and Eastern European region (CEE) to pass antitobacco legislation. ${ }^{11}$ The law, which went into effect on 1 May 1996, prohibited smoking on the premises of: (1) healthcare establishments; (2) educational institutions and (3) enclosed workplaces and other premises designated for public use. ${ }^{12}$ The smoke-free law has been amended several times since its inception. ${ }^{11}{ }^{12}$ In 2010 , the law was expanded to include additional settings such as transport services, food and hospitality establishments as well as culture and recreation establishments (table 1). Moreover, prominent no-smoking signage using text and graphic markings were required in given indoor areas or public transport vehicles. ${ }^{11} 12$ The prohibition was further extended in 2016 to include electronic cigarettes (e-cigarettes) and novel tobacco products (such as heated tobacco products). Despite incremental improvements, the law does not provide comprehensive protection for indoor settings. Exemptions in the form of a designated smoking room have been made for: (1) nursing homes or retirement homes; (2) hotels; (3) traveller service venues (railways, airports); (4) higher education institutions; (5) workplaces and (6) dining and entertainment venues. ${ }^{12}$ For example, in the case of restaurants or bars with at least two rooms, the owner may designate a ventilated room where smoking is allowed. ${ }^{12}$ Because smoking is not completely prohibited (because of exemptions indicated above), Poland has not adopted a comprehensive prohibition on indoor smoking. Currently, available data show that designated/ventilated areas cannot eliminate SHS exposure. ${ }^{34}$ The most effective evidence-based strategy is to prohibit indoor smoking completely with no exemption for smoking rooms. ${ }^{47}$

The prevalence of tobacco use in Poland is regularly monitored using a national cross-sectional survey. Between 2009 and 2019, the prevalence of adult smoking (aged 15 and over) decreased from $35.0 \%$ to $24.4 \%$ among males, and from $24.0 \%$ to $18.0 \%$ among females. ${ }^{13}$ However, since the amendment of the smokefree law in $2010,{ }^{12}$ national estimates of the prevalence of SHS exposure have not been documented. Moreover, the relative impact of the smoking prohibition on SHS exposure across a diverse range of indoor settings on SHS is unknown. Because different types of venues support different modes of use by members of the public (eg, food and hospitality establishments compared with transport services) we sought to understand the implications for policy adherence, as measured by SHS exposure across different venue types.

The objectives of this study were (1) to assess changes in self-reported prevalence of SHS exposure in workplaces and public venues among a nationally representative samples of adults in Poland, and (2) to assess the impact of the implemented tobacco control law by specific venue type, as measured by venue-specific self-reported SHS exposure rates. 


\section{METHODS}

\section{Study design and sample}

Data were obtained from nationally representative cross-sectional surveys (six waves: 2009, $\mathrm{n}=1003$; 2011, $\mathrm{n}=1005 ; 2013, \mathrm{n}=1002 ; 2015, \mathrm{n}=1004 ; 2017, \mathrm{n}=1042 ; 2019$, $\mathrm{n}=1011$ ) carried out by the Chief Sanitary Inspectorate (Warsaw, Poland). ${ }^{13}$ The Chief Sanitary Inspectorate is a public administration authority tasked with the oversight of public health services in Poland, including monitoring of key tobacco control indicators. The Chief Sanitary Inspectorate conducts a national cross-sectional survey on tobacco use in Poland every 2 years, using a representative sample of adults aged 15 years of age and older. The stratification model includes gender, age, as well as the size of domicile and the territorial distribution within administrative regions ('voivodeships'). ${ }^{14}$ A random quota sample was used which ensures a random selection of locations for the survey and guarantees that the sample structure corresponds with the population structure. ${ }^{14}$ All interviews across the six survey waves were carried out by a specialised survey company on behalf of the Chief Sanitary Inspectorate. ${ }^{13}$

\section{Participants and public involvement}

Participants in this study were not involved in the development of the design, recruitment. Results will be disseminated via publication in an open access journal.

\section{Measures}

Each of the six survey waves included questions on lifetime and current tobacco and e-cigarette use and selfreported SHS exposure in public venues. ${ }^{13}$ The study questionnaire is based on questions used in the Global Adult Tobacco Survey. ${ }^{15}$ The questionnaire is updated with each wave to include questions on new nicotinecontaining products (eg, e-cigarettes or heated tobacco products) that appear on the market.

Tobacco and e-cigarette use: Lifetime smoking status was defined using the question: 'Have you ever smoked at least 100 cigarettes (or similar amount of other tobacco products for example, pipes, cigars, cigarillos) in your lifetime?' and 'Do you currently smoke?'. Smokers (current active smokers) were defined as having smoked $\geq 100$ cigarettes (or other tobacco products) during their lifetime and who currently smoke. For the purpose of the analysis, non-smokers were defined as having smoked fewer than 100 cigarettes during their lifetime and not currently smoke (never-smokers) as well as those having smoked at least 100 cigarettes during their lifetime and do not currently smoke (ex-smokers).

SHS exposure in public venues: Exposure to SHS in public venues was assessed using the question: 'Considering the last month, were you exposed to SHS (anyone smoke inside) in the following places: your workplace; healthcare establishments; public agencies and government institutions; educational institutions and universities; public transport stops and facilities; public transportation vehicles; bar/pub; shopping centres or culture facilities; sport facilities; leisure facilities; and play areas for children. Respondents who indicated 'yes' were classified as exposed to SHS in a given place. The text and wording of the questions related to SHS exposure in public places were identical in all six survey waves. Venues were categorised into four major types: (1) workplace and public facilities; (2) transport services; (3) food and hospitality establishments and (4) culture and recreation establishments. Categorisation was based on the type of activity performed in a given place.

\section{Data analysis}

The data were analysed with SPSS V.25 (IBM). The distribution of categorical variables was shown by frequencies and proportions with 95\% CI. Demographic weighting was applied (age, gender and geographical location). Differences in response estimates were considered statistically significant if $95 \%$ CIs did not overlap. For each year, the prevalence of SHS exposure in each venue type was calculated overall and among non-smokers by sex, when sufficient sample size allowed. Self-reported SHS exposure was reported by specific venue type. To identify differences in SHS exposure by venue type, the venues were categorised according to four major primary use purposes: workplace and public facilities; transport facilities; food and hospitality establishments; and cultural and leisure facilities. Separate analyses were not conducted for smokers, because of problems distinguishing SHS selfexposure from SHS exposure arising from other sources.

\section{RESULTS}

The demographic characteristics of the study sample are presented in table 2. The proportion of non-smokers increased from $70.8 \%$ in 2009 to $79.0 \%$ in 2019. The proportions of respondents who reported SHS exposure are presented in table 3, by gender and for each of 13 venue types.

\section{SHS exposure in the workplace}

In 2009, one in four of all respondents (25.4\%) were exposed to SHS in Polish workplaces, with higher levels of exposure among males than females (table 3). Between 2009 and 2019, the number of respondents reporting SHS exposure in the workplace decreased by $73.6 \%$ (from $25.4 \%$ to $6.7 \%$ ). Within a year of adopting the amendment to the tobacco control act in 2010, the proportion of non-smokers exposed to SHS in the workplace decreased by half (from $19.2 \%$ in 2009 to $9.5 \%$ in 2011).

\section{SHS exposure in other public places}

Among the 12 types of public places analysed in this study, the highest levels of SHS exposure in any observation year between 2009oc and 19oc curred in public transport stops and facilities and bars/pubs: this outcome was seen in all respondents and the non-smoker subsample (tables 3 and 4). Between 2009 and 2019, the proportion of participants exposed to SHS in public transport stops and facilities 


\begin{tabular}{|c|c|c|c|c|c|c|}
\hline Study year (wave) & 2009 & 2011 & 2013 & 2015 & 2017 & 2019 \\
\hline All respondents & $n=1003$ & $n=1005$ & $n=1002$ & $n=1004$ & $n=1042$ & $\mathrm{n}=1011$ \\
\hline \multicolumn{7}{|l|}{ Male } \\
\hline $\mathrm{n}$ & 478 & 479 & 477 & 481 & 499 & 484 \\
\hline$\%$ & $47.7(44.6-50.8)$ & $47.7(44.6-50.8)$ & $47.6(44.5-50.7)$ & $47.9(44.8-51.0)$ & $47.9(44.9-50.9)$ & $47.9(44.8-51.0)$ \\
\hline \multicolumn{7}{|l|}{ Female } \\
\hline $\mathrm{n}$ & 525 & 526 & 525 & 523 & 543 & 527 \\
\hline$\%$ & $52.3(49.3-55.4)$ & $52.3(49.3-55.4)$ & $52.4(49.3-55.5)$ & $52.1(49.0-55.2)$ & $52.1(49.1-55.1)$ & $52.1(49.1-55.2)$ \\
\hline \multicolumn{7}{|l|}{ Non-smokers } \\
\hline \multicolumn{7}{|l|}{ Overall } \\
\hline $\mathrm{n}$ & 710 & 694 & 733 & 763 & 789 & 798 \\
\hline$\%$ & 70.8 (67.9-73.5) & $69.1(66.1-71.8)$ & $73.2(70.3-75.8)$ & $76.0(73.3-78.5)$ & 75.7 (73.0-78.2) & 79.0 (76.3-81.3) \\
\hline \multicolumn{7}{|l|}{ Male } \\
\hline$n$ & 311 & 291 & 329 & 333 & 355 & 366 \\
\hline$\%$ & $65.1(60.7-69.2)$ & $60.8(56.3-65.0)$ & $69.0(64.7-73.0)$ & $69.2(65.0-73.2)$ & $71.1(67.0-74.9)$ & 75.6 (71.6-79.2) \\
\hline \multicolumn{7}{|l|}{ Female } \\
\hline $\mathrm{n}$ & 399 & 403 & 404 & 430 & 434 & 432 \\
\hline$\%$ & 76.0 (72.2-79.5) & 76.6 (72.8-80.0) & $77.0(73.2-80.4)$ & $82.2(78.7-85.3)$ & 79.9 (76.4-83.1) & $82.0(78.5-85.0)$ \\
\hline
\end{tabular}

decreased from $45.7 \%$ to $11.7 \%$ among all respondents and from $44.2 \%$ to $11.7 \%$ among non-smokers (a $73.5 \%$ decrease over 10 years). An even greater decrease in SHS exposure was observed for bars/pubs, between 2009 and 2019 SHS exposure in bars/pubs decreased $84 \%$ among all respondents (from $45.0 \%$ to $7.0 \%$ ) and by $82 \%$ among non-smokers (from $39.4 \%$ to $7.0 \%$ ) (table 4). Moreover, no significant differences in SHS exposure in bars/pubs were observed between men and women after 2013.

A substantial reduction in self-reported SHS exposure was also observed in sports facilities, leisure facilities and play areas for children. Among all respondents, exposure to SHS decreased by $86 \%$ in both sports facilities (from $20.0 \%$ to $2.9 \%$ ) and leisure facilities (from $21.6 \%$ to $3.1 \%$ ). Among non-smokers, exposure to SHS in sports facilities decreased by $79.2 \%$ (from $16.8 \%$ to $3.5 \%$ ) and in leisure facilities decreased by $79.8 \%$ (from $19.2 \%$ to $3.4 \%)$. At the same time (2009-2019) exposure to SHS in play areas for children decreased by $84.3 \%$ (from $13.4 \%$ to $2.1 \%$ ) among all respondents, and by $81.1 \%$ (from $11.1 \%$ to $2.1 \%$ ) among non-smokers (table 4 ).

In 2009, the lowest rate of self-reported SHS exposure was in culture facilities and shopping centres. Between 2009 and 2019, exposure to SHS in shopping centres or culture facilities halved among all respondents and nonsmokers. Detailed data on SHS exposure in the 12 public venues analysed in this study are presented in tables 3 and 4.

\section{DISCUSSION}

This study used data from six waves of nationwide crosssectional surveys (carried out every 2 years since 2009) to assess self-reported exposure to SHS in homes, workplaces and 12 different public venues in Poland. Our findings indicate that between 2009 and 2019 SHS exposure in workplaces and other public places dropped dramatically. The greatest biennial decrease in SHS exposure was observed in 2011, following the introduction of the smoke-free policy in Poland in 2010. From 2011 to 2019, the trend towards lowered SHS exposure continued, although more modestly, with the attainment of an historic low rate of SHS exposure in the most recent survey year. While self-reported SHS exposure was generally higher across all venue type in the general adult population ('all respondents') compared with non-smokers, this difference was only significant in workplaces in 2009, and the gap had closed by 2011. This finding suggests that also smokers are driving the change over time. Between 2009 and 2019, SHS exposure among non-smokers decreased by $76 \%$ in public agencies and government institutions, and as much as $84 \%$ in bars and pubs. SHS exposure tended to be higher overall among males, but this difference was significant only in certain venues such as workplaces, public transportation, bars/pubs and the gender gap had closed by 2013 .

While numerous studies have assessed the effect of smoke-free laws and policies in reducing exposure to SHS, most are limited to relatively short-term outcomes of 1-2 years following policy adoption in contrast to this study which measured full decade. ${ }^{16-18}$ According to the Special Eurobarometer 385, SHS exposure among EU citizens visiting bars and pubs dropped from $46 \%$ in 2009 to $28 \%$ in 2012. ${ }^{18}$ Similarly, among citizens visiting restaurants, SHS exposure dropped from $31 \%$ to $14 \%$ between 2009 and 2012. ${ }^{18}$ In 2012, the highest level of SHS exposure in bars and pubs was observed in Greece $(71 \%)$, Bulgaria 
Table 3 Percentage of population reporting secondhand smoke exposure in workplace, healthcare establishments, public agencies, educational institutions and transport services in years 2009-2019, overall and among non-smokers, by sex

$\begin{array}{lcc}\text { Year } & \text { Overall } & \text { Males } \\ & \text { Workplace and public facilities } \%(95 \% \mathrm{Cl})\end{array}$

\section{Workplaces}

All respondents

$\begin{array}{lccc}2009 & 25.4(22.8 \text { to } 28.2) & 31.8(27.8 \text { to } 36.1) & 19.6(16.5 \text { to } 23.2) \\ 2011 & 13.6(11.7 \text { to } 15.9) & 18.6(15.4 \text { to } 22.3) & 9.1(7.0 \text { to } 11.9) \\ 2013 & 7.2(5.7 \text { to } 9.0) & 8.8(6.6 \text { to } 11.7) & 5.7(4.0 \text { to } 8.0) \\ 2015 & 10.8(9.0 \text { to } 12.8) & 12.1(9.4 \text { to } 15.3) & 9.6(7.3 \text { to } 12.4) \\ 2017 & 7.9(6.4 \text { to } 9.7) & 9.6(7.3 \text { to } 12.5) & 6.3(4.5 \text { to } 8.6) \\ 2019 & 6.7(5.3 \text { to } 8.4) & 7.4(5.4 \text { to } 10.1) & 6.1(4.3 \text { to } 8.5)\end{array}$

Non-smokers

\begin{tabular}{|lccc}
\hline 2009 & $19.2(16.4$ to 22.2$)$ & $23.2(18.8$ to 28.2$)$ & $16.4(12.8$ to 20.0$)$ \\
\hline 2011 & $9.5(7.6$ to 11.9$)$ & $13.1(9.7$ to 17.4$)$ & $7.0(4.9$ to 9.9$)$ \\
\hline 2013 & $6.8(5.2$ to 8.9$)$ & $7.9(5.5$ to 11.3$)$ & $5.9(4.0$ to 8.7$)$ \\
\hline 2015 & $10.1(8.2$ to 12.4$)$ & $12.9(9.7$ to 16.9$)$ & $7.9(5.7$ to 10.9$)$ \\
\hline 2017 & $6.8(5.3$ to 8.8$)$ & $7.9(5.5$ to 11.2$)$ & $6.0(4.1$ to 8.6$)$ \\
\hline
\end{tabular}

Healthcare establishments

All respondents

\begin{tabular}{|c|c|c|c|}
\hline 2009 & $11.2(9.4$ to 13.3$)$ & 11.1 (8.6 to 14.2$)$ & 8.0 (6.0 to 10.6$)$ \\
\hline 2011 & 4.0 (2.9 to 5.4$)$ & 3.8 (2.4 to 5.9$)$ & $4.2(2.8$ to 6.3$)$ \\
\hline 2013 & 2.6 (1.8 to 3.8$)$ & 1.7 (0.9 to 3.3$)$ & $3.4(2.2$ to 5.4$)$ \\
\hline 2015 & 3.5 (2.5 to 4.8 ) & 2.9 (1.7 to 4.8$)$ & $4.0(2.6$ to 6.1$)$ \\
\hline 2017 & $2.4(1.6$ to 3.5$)$ & $2.0(1.1$ to 3.7$)$ & $2.8(1.7$ to 4.5$)$ \\
\hline 2019 & $2.3(1.5$ to 3.4$)$ & 2.7 (1.6 to 4.5$)$ & 1.9 (1.0 to 3.5$)$ \\
\hline \multicolumn{4}{|c|}{ Non-smokers } \\
\hline 2009 & $7.9(6.1$ to 10.1$)$ & $9.0(6.3$ to 12.7$)$ & 7.0 (4.9 to 10.0$)$ \\
\hline 2011 & $4.0(2.8$ to 5.8$)$ & $4.1(2.4$ to 7.1$)$ & $4.0(2.5$ to 6.4$)$ \\
\hline 2013 & $3.0(2.0$ to 4.5$)$ & $1.8(0.8$ to 3.9$)$ & $4.0(2.5$ to 6.3$)$ \\
\hline 2015 & $3.5(2.4$ to 5.1$)$ & $3.0(1.6$ to 5.4$)$ & $4.0(2.5$ to 6.2$)$ \\
\hline 2017 & 2.5 (1.7 to 3.9$)$ & 2.0 (1.0 to 4.0$)$ & $3.0(1.8$ to 5.1$)$ \\
\hline 2019 & 2.5 (1.6 to 3.8$)$ & 3.0 (1.7 to 5.3$)$ & 2.1 (1.1 to 3.9$)$ \\
\hline \multicolumn{4}{|c|}{ Public agencies and government institutions } \\
\hline \multicolumn{4}{|c|}{ All respondents } \\
\hline 2009 & 9.5 (7.8 to 11.4$)$ & $8.4(6.2$ to 11.2$)$ & 7.4 (5.5 to 10.0$)$ \\
\hline 2011 & 4.7 (3.5 to 6.2$)$ & 3.8 (2.4 to 5.9$)$ & 5.5 (3.9 to 7.8$)$ \\
\hline 2013 & 2.3 (1.5 to 3.4 ) & 2.7 (1.6 to 4.6$)$ & 1.9 (1.0 to 3.5$)$ \\
\hline 2015 & 3.1 (2.2 to 4.4 ) & 2.9 (1.7 to 4.8$)$ & 3.3 (2.0 to 5.1$)$ \\
\hline 2017 & 3.3 (2.3 to 4.5$)$ & 3.4 (2.1 to 5.4$)$ & 3.1 (2.0 to 5.0$)$ \\
\hline 2019 & 2.3 (1.5 to 3.4 ) & 2.7 (1.6 to 4.5 ) & 1.9 (1.0 to 3.5$)$ \\
\hline \multicolumn{4}{|c|}{ Non-smokers } \\
\hline 2009 & 6.5 (4.9 to 8.5$)$ & 7.1 (4.7 to 10.5$)$ & 6.0 (4.1 to 8.8$)$ \\
\hline 2011 & 4.6 (3.3 to 6.4$)$ & 4.1 (2.4 to 7.1$)$ & 5.0 (3.2 to 7.5$)$ \\
\hline 2013 & 2.5 (1.6 to 3.9$)$ & 3.0 (1.7 to 5.5$)$ & 2.0 (1.0 to 3.9$)$ \\
\hline 2015 & 3.0 (2.0 to 4.5$)$ & 3.0 (1.6 to 5.4$)$ & $3.0(1.8$ to 5.1$)$ \\
\hline
\end{tabular}


Table 3 Continued

\begin{tabular}{cccc}
\hline Year & Overall & Males & Females \\
\hline 2017 & $3.0(2.1$ to 4.5$)$ & $3.1(1.7$ to 5.5$)$ & $3.0(1.8$ to 5.1$)$ \\
2019 & $2.5(1.6$ to 3.8$)$ & $3.0(1.7$ to 5.3$)$ & 2.1 (1.1 to 3.9)
\end{tabular}

Educational institutions

All respondents

\begin{tabular}{|c|c|c|c|}
\hline 2009 & 11.2 (9.4 to 13.3 ) & 11.1 (8.6 to 14.2$)$ & 11.2 (8.8 to 14.2$)$ \\
\hline 2011 & 7.7 (6.2 to 9.5$)$ & 8.4 (6.2 to 11.2$)$ & 7.0 (5.2 to 9.6$)$ \\
\hline 2013 & 2.3 (1.5 to 3.4 ) & 2.9 (1.8 to 4.9$)$ & 1.7 (0.9 to 3.2$)$ \\
\hline 2015 & 3.6 (2.6 to 4.9 ) & 3.3 (2.1 to 5.3 ) & 3.8 (2.5 to 5.8$)$ \\
\hline 2017 & 3.7 (2.7 to 5.0$)$ & 3.6 (2.3 to 5.6$)$ & 3.7 (2.4 to 5.6$)$ \\
\hline 2019 & 3.0 (2.1 to 4.2 ) & 3.9 (2.5 to 6.1$)$ & 2.1 (1.2 to 3.7$)$ \\
\hline \multicolumn{4}{|c|}{ Non-smokers } \\
\hline 2009 & 10.1 (8.1 to 12.6$)$ & 9.0 (6.3 to 12.7$)$ & 11.0 (8.3 to 14.5 ) \\
\hline 2011 & 8.2 (6.4 to 10.5$)$ & $10.0(7.0$ to 14.0$)$ & 7.0 (4.9 to 9.9$)$ \\
\hline 2013 & 2.5 (1.6 to 3.9 ) & 3.0 (1.7 to 5.5$)$ & 2.0 (1.0 to 3.9 ) \\
\hline 2015 & 3.9 (2.8 to 5.6$)$ & 3.9 (2.3 to 6.6$)$ & 4.0 (2.5 to 6.2$)$ \\
\hline 2017 & 3.9 (2.8 to 5.5$)$ & 3.9 (2.4 to 6.5$)$ & 3.9 (4.5 to 6.2 ) \\
\hline 2019 & 3.4 (2.3 to 4.9$)$ & 4.9 (3.1 to 7.6$)$ & 2.1 (1.1 to 3.9$)$ \\
\hline
\end{tabular}

Public transport stops and facilities

Transport services $\%(95 \% \mathrm{Cl})$

All respondents

\begin{tabular}{|c|c|c|c|}
\hline 2009 & 45.7 (42.6 to 48.8 ) & 47.7 (43.2 to 52.2 ) & 43.8 (39.6 to 48.1$)$ \\
\hline 2011 & 30.4 (27.6 to 33.3 ) & 33.0 (28.9 to 37.3 ) & 28.0 (24.3 to 31.9$)$ \\
\hline 2013 & 26.5 (23.8 to 29.3 ) & 24.1 (20.5 to 28.1$)$ & 28.6 (24.9 to 32.6$)$ \\
\hline 2017 & 23.4 (21.0 to 28.1$)$ & 21.0 (17.7 to 24.8$)$ & 25.6 (22.1 to 29.4) \\
\hline 2019 & 11.7 (9.8 to 13.8) & $11.2(8.7$ to 14.3$)$ & 12.1 (9.6 to 15.2$)$ \\
\hline 2009 & 44.2 (40.6 to 47.9 ) & 47.0 (41.5 to 52.5$)$ & 42.1 (37.4 to 47.0$)$ \\
\hline 2011 & 29.0 (25.7 to 32.5$)$ & 33.0 (27.8 to 38.6 ) & 26.1 (22.0 to 30.6$)$ \\
\hline 2013 & 27.2 (24.1 to 30.5$)$ & 24.9 (20.6 to 29.9) & 29.0 (24.8 to 33.6) \\
\hline 2015 & 27.4 (24.4 to 30.7$)$ & 29.1 (24.5 to 34.2 ) & 26.1 (22.1 to 30.4$)$ \\
\hline 2017 & 23.8 (21.0 to 26.9 ) & 21.1 (17.2 to 25.7$)$ & 26.0 (22.1 to 30.4$)$ \\
\hline 2009 & 15.6 (13.4 to 17.9$)$ & 19.0 (15.8 to 22.8 ) & 12.4 (9.8 to 15.5$)$ \\
\hline 2011 & 6.4 (5.0 to 8.1$)$ & 5.6 (4.1 to 8.3$)$ & 6.8 (5.0 to 9.3 ) \\
\hline 2013 & 4.6 (3.5 to 6.1$)$ & $4.6(3.1$ to 6.9$)$ & 4.6 (3.1 to 6.7$)$ \\
\hline 2015 & 6.6 (5.2 to 8.3$)$ & 7.7 (5.6 to 10.4$)$ & 5.5 (3.9 to 7.9$)$ \\
\hline 2017 & 3.7 (2.8 to 5.1$)$ & 4.2 (2.8 to 6.4$)$ & 3.3 (2.1 to 5.2$)$ \\
\hline 2019 & 3.1 (2.2 to 4.3$)$ & 3.5 (2.2 to 5.6$)$ & 2.7 (1.6 to 4.4$)$ \\
\hline \multicolumn{4}{|c|}{ Non-smokers } \\
\hline 2009 & $13.9(11.6$ to 16.7$)$ & 19.0 (15.0 to 23.7$)$ & $10.0(7.5$ to 13.4$)$ \\
\hline
\end{tabular}




\begin{tabular}{cccc}
\hline Table 3 & Continued & & \\
\hline Year & Overall & Males & Females \\
\hline 2015 & $7.7(6.0$ to 9.9$)$ & $9.9(7.1$ to 13.6$)$ & $6.1(4.2$ to 8.7$)$ \\
2017 & $3.9(2.8$ to 5.5$)$ & $3.9(2.4$ to 6.5$)$ & $3.9(2.5$ to 6.2$)$ \\
2019 & $3.0(2.0$ to 4.4$)$ & $3.0(1.7$ to 5.3$)$ & $3.0(1.8$ to 5.1$)$
\end{tabular}

$(69 \%)$ and Luxembourg $(68 \%) \cdot{ }^{18}$ In contrast, the lowest rates of SHS in bars and pubs were observed in Belgium, Spain and Poland, which were mentioned by the European Commission as exemplars of countries where the adoption of smoke-free law led to very significant drops in SHS exposure within a short time. ${ }^{5}$ The present findings maintain the pattern of observation reported in Poland and elsewhere in the EU by Eurobarometer. The present findings also point to the benefit of ongoing, biennial surveys of SHS exposure, which allow changes to be closely monitored across an extended period.

The present findings also occur in the context of substantial changes in public SHS exposure in both developed and low/middle-income countries outside the EU. According to the US Centers for Disease Control and Prevention, the prevalence of SHS exposure among US non-smokers declined substantially during 1988-2014, from $87.5 \%$ to $25.2 \% .{ }^{16}$ Nonetheless, large variations in SHS exposure continue to be observed globally. For example, workplace SHS exposure as low as $26.8 \%$ has been reported in Korea, ${ }^{19}$ in contrast to $63.3 \%$ of workers in China. ${ }^{20}$

In 2017, the overall prevalence of SHS exposure among EU citizens visiting bars was 20\%, with $9 \%$ reporting SHS exposure when visiting restaurants. ${ }^{6}$ However, higher rates are observed in the CEE region: SHS exposure rates in bars are as high as $73 \%$ in the Czech Republic, $50 \%$ in Slovakia and $42 \%$ in Bulgaria. These countries also report high rates of exposure in restaurants: Czech Republic (49\%), Bulgaria (25\%) and Slovakia (18\%). In contrast, only $14 \%$ of Poles report SHS exposure in bars and $6 \%$ report exposure in restaurants. ${ }^{6}$ These differences exist despite all of the cited CEE countries having adopted smoke-free laws. The reasons for the variation in SHS exposure across CEE countries is likely complex, incorporating factors such as social support, the period of time the policy has been in effect and differences in the quality and scope of strategies used to implement smokefree policies in each country.

Poland is perceived as a CEE regional leader of tobacco control policy and practice. ${ }^{11}$ While there is still much to be done to ensure protection from SHS in eastern Europe and globally, certain lessons may be gleaned from the present findings to inform the implementation of smoke-free policies, particularly in other CEE countries.

In Poland, the same smoke-free policy produced markedly different outcomes in SHS exposure reduction across different types of venues, a decade after adoption. In 2019, 11.7\% of Poles reported SHS exposure in transport facilities while $7.0 \%$ were exposed to SHS in hospitality establishments, particularly bars and pubs. These differences suggest that different SHS policy implementation strategies may be needed in locations with higher SHS exposure. Successful policy implementation is a complex process, ideally supported by evidence-informed implementation strategies. The adoption of smoke-free workplace laws and other regulations to protect the public from SHS in public places in early-adopting jurisdictions, such as in the USA, yielded little effect without such dedicated implementation and enforcement efforts. ${ }^{21-23}$ Accordingly, Poland's Chief Sanitary Inspectorate used several key implementation approaches, before adoption, to inform and prepare the public about the rationale for the prohibition and the scope of the rule. The introduction of the smoking prohibition was accompanied by a nationwide media campaign in 2010 (television broadcast on most-watched networks) which provided information on changes to national tobacco policy, with particular emphasis on the impending smoking prohibition in workplaces and public venues. ${ }^{24}$ Other educational activities were carried out both at the national and regional level. For example, school-based educational campaigns 'Don't smoke around me' and 'Clean-air around us' were targeted towards children and their parents. ${ }^{24}$ Another key implementation strategy has been ongoing monitoring of compliance. The legal obligations for property owners and managers were strictly and clearly defined, requiring owners or managers of venues to place appropriate text and graphical signs informing staff and visitors about the smoking prohibition in a visible location. ${ }^{12}$ Enforcement of the policy is delegated to the Chief Sanitary Inspectorate who conduct inspections to verify compliance in workplaces and other venues covered by the prohibition. In 2011, 99.7\% of 273137 venues inspected met the requirements of the smoke-free law. ${ }^{25}$ In 2018, violations of smoke-free law implementation were observed in fewer than $0.05 \%$ of controlled places. ${ }^{25}$ Violations are met with the issuing of fines (up to 500 polish złoty: equivalent to $€ 110$ ). Although Poland does not have a comprehensive smoking prohibition, comprehensive prohibitions have generally been found to be more effective than partial prohibitions, which offer easily exploited loopholes. ${ }^{26}{ }^{27}$ Further legislative intervention would be required to adopt comprehensive smoking prohibition in workplaces and public venues by eliminating smoking rooms. 
Table 4 Percentage of population exposed to secondhand smoke in food and hospitality establishments, as well as in culture and recreation establishments in years 2009-2019, overall and among non-smokers, by sex

\begin{tabular}{|c|c|c|c|}
\hline Year & Overall & Males & Females \\
\hline \multicolumn{4}{|c|}{ Food and hospitality establishments \% (95\% Cl) } \\
\hline \multicolumn{4}{|c|}{ Bar/Pub } \\
\hline \multicolumn{4}{|c|}{ All respondents } \\
\hline 2009 & 45.0 (41.9 to 48.1$)$ & 54.8 (50.3 to 59.2$)$ & 45.0 (41.9 to 48.1$)$ \\
\hline 2011 & 19.6 (17.3 to 22.2 ) & 24.2 (20.6 to 28.3) & 19.6 (17.3 to 22.2 ) \\
\hline 2013 & 18.7 (16.4 to 21.2 ) & 22.2 (18.7 to 26.2 ) & 18.7 (16.4 to 21.2$)$ \\
\hline 2015 & 15.6 (13.5 to 18.0$)$ & 17.3 (14.1 to 20.9$)$ & 15.6 (13.5 to 18.0$)$ \\
\hline 2017 & 12.5 (10.6 to 14.6$)$ & 14.4 (11.6 to 17.8$)$ & 12.5 (10.6 to 14.6$)$ \\
\hline 2019 & 7.0 (5.6 to 8.8 ) & 8.1 (6.0 to 10.8$)$ & 7.0 (5.6 to 8.8 ) \\
\hline \multicolumn{4}{|c|}{ Non-smokers } \\
\hline 2009 & 39.4 (35.9 to 43.1$)$ & 48.9 (43.4 to 54.4$)$ & 39.4 (35.9 to 43.1 ) \\
\hline 2011 & 17.4 (14.8 to 20.4$)$ & 21.0 (16.7 to 26.0$)$ & 17.4 (14.8 to 20.4$)$ \\
\hline 2013 & 18.8 (16.2 to 21.8$)$ & 21.0 (16.9 to 25.7) & 18.8 (16.2 to 21.8$)$ \\
\hline 2015 & 16.6 (14.2 to 19.5$)$ & 20.1 (16.2 to 24.8$)$ & 16.6 (14.2 to 19.5$)$ \\
\hline 2017 & 12.4 (10.3 to 14.9$)$ & 14.1 (10.9 to 18.1$)$ & 12.4 (10.3 to 14.9 ) \\
\hline 2019 & 7.0 (5.4 to 9.0$)$ & 7.1 (4.9 to 10.2 ) & 7.0 (5.4 to 9.0 ) \\
\hline
\end{tabular}

\section{Restaurant}

All respondents

\begin{tabular}{|c|c|c|c|}
\hline 2009 & $28.8(26.1$ to 31.7$)$ & 34.1 (30.0 to 38.5$)$ & $24.0(20.5$ to 27.8$)$ \\
\hline 2011 & $9.6(7.9$ to 11.5$)$ & $11.3(8.7$ to 14.4$)$ & $8.0(6.0$ to 10.6$)$ \\
\hline 2013 & 6.3 (5.0 to 8.0$)$ & $7.3(5.3$ to 10.0$)$ & $5.3(3.7$ to 7.6$)$ \\
\hline 2015 & 6.9 (5.5 to 8.6$)$ & 4.8 (3.2 to 7.1$)$ & $8.8(6.7$ to 11.5$)$ \\
\hline 2017 & 7.1 (5.7 to 8.8$)$ & $8.0(5.9$ to 10.7$)$ & $6.3(4.5$ to 8.6$)$ \\
\hline 2019 & 4.6 (3.4 to 6.0$)$ & 4.3 (2.9 to 6.5$)$ & 4.7 (3.2 to 6.9$)$ \\
\hline \multicolumn{4}{|c|}{ Non-smokers } \\
\hline 2009 & $25.9(22.8$ to 29.3$)$ & 30.9 (26.0 to 36.2$)$ & 22.1 (18.3 to 26.4$)$ \\
\hline 2011 & $8.4(6.5$ to 10.7$)$ & $8.9(6.2$ to 12.8$)$ & $7.9(5.7$ to 11.0$)$ \\
\hline 2013 & 6.8 (5.2 to 8.9$)$ & 7.9 (5.5 to 11.3$)$ & 5.9 (4.0 to 8.7$)$ \\
\hline 2015 & 6.7 (5.1 to 8.7$)$ & $5.1(3.2$ to 8.0$)$ & 7.9 (5.7 to 10.9$)$ \\
\hline 2017 & 7.4 (5.7 to 9.4$)$ & 7.9 (5.5 to 11.2$)$ & 6.9 (4.9 to 9.7$)$ \\
\hline 2019 & 4.6 (3.4 to 6.3$)$ & 4.1 (2.5 to 6.7$)$ & 5.1 (3.4 to 7.6$)$ \\
\hline \multicolumn{4}{|c|}{ Cultural and recreation facilities $\%(95 \% \mathrm{Cl})$} \\
\hline \multicolumn{4}{|c|}{ Cultural facilities } \\
\hline \multicolumn{4}{|c|}{ All respondents } \\
\hline 2009 & $5.6(4.3$ to 7.2$)$ & 5.7 (3.9 to 8.1$)$ & 5.5 (3.9 to 7.8$)$ \\
\hline 2011 & 4.7 (3.5 to 6.2$)$ & 3.8 (2.4 to 5.9 ) & 5.5 (3.9 to 7.8 ) \\
\hline 2013 & 1.9 (1.2 to 2.9$)$ & 1.9 (1.0 to 3.6$)$ & 1.9 (1.0 to 3.5$)$ \\
\hline 2015 & 3.6 (2.6 to 4.9 ) & 2.7 (1.6 to 4.6$)$ & 4.4 (3.0 to 6.5$)$ \\
\hline 2017 & 2.4 (1.6 to 3.5 ) & 2.2 (1.2 to 3.9 ) & 2.6 (1.5 to 4.3 ) \\
\hline 2019 & 2.0 (1.3 to 3.0$)$ & $1.2(0.6$ to 2.7$)$ & 2.7 (1.6 to 4.4$)$ \\
\hline \multicolumn{4}{|c|}{ Non-smokers } \\
\hline 2009 & 4.5 (3.2 to 6.3$)$ & 3.9 (2.2 to 6.6$)$ & 5.0 (3.3 to 7.6$)$ \\
\hline 2011 & 4.2 (2.9 to 5.9$)$ & 3.1 (1.6 to 5.8 ) & 5.0 (3.2 to 7.5$)$ \\
\hline 2013 & 1.5 (0.8 to 2.7$)$ & 0.9 (0.3 to 2.7$)$ & 2.0 (1.0 to 3.9$)$ \\
\hline
\end{tabular}


Table 4 Continued

\begin{tabular}{|llll}
\hline Year & Overall & Males & Females \\
\hline 2015 & $3.5(2.4$ to 5.1$)$ & $3.0(1.6$ to 5.4$)$ & $4.0(2.5$ to 6.2$)$ \\
2017 & $2.5(1.7$ to 3.9$)$ & $2.0(1.0$ to 4.0$)$ & $3.0(1.8$ to 5.1$)$ \\
2019 & $2.1(1.3$ to 3.4$)$ & $1.1(0.4$ to 2.8$)$ & $3.0(1.8$ to 5.1$)$ \\
\hline
\end{tabular}

\section{Shopping centres}

\begin{tabular}{|c|c|c|c|}
\hline \multicolumn{4}{|c|}{ All respondents } \\
\hline 2009 & 7.9 (6.4 to 9.7$)$ & 9.4 (7.1 to 12.4$)$ & 6.5 (4.7 to 8.9$)$ \\
\hline 2011 & 5.9 (4.6 to 7.5$)$ & 5.9 (4.1 to 8.3$)$ & 5.9 (4.2 to 8.2$)$ \\
\hline 2013 & 3.2 (2.3 to 4.5$)$ & 2.5 (1.4 to 4.4$)$ & 3.8 (2.5 to 5.8 ) \\
\hline 2015 & 5.4 (4.2 to 7.0$)$ & 4.4 (2.9 to 6.6$)$ & 6.3 (4.5 to 8.7 ) \\
\hline 2017 & 5.2 (4.0 to 6.7$)$ & 4.2 (2.8 to 6.4 ) & 6.1 (4.4 to 8.4$)$ \\
\hline 2019 & 3.6 (2.6 to 4.9 ) & 4.3 (2.9 to 6.5$)$ & 2.9 (1.7 to 4.6$)$ \\
\hline \multicolumn{4}{|c|}{ Non-smokers } \\
\hline 2009 & 6.8 (5.1 to 8.9 ) & 9.0 (6.3 to 12.7$)$ & 5.0 (3.3 to 7.6$)$ \\
\hline 2011 & 5.9 (4.4 to 7.9$)$ & 5.8 (3.7 to 9.2 ) & 6.0 (4.0 to 8.7$)$ \\
\hline 2013 & 3.6 (2.4 to 5.2$)$ & 3.0 (1.7 to 5.5$)$ & 4.0 (2.5 to 6.3 ) \\
\hline 2015 & 5.6 (4.2 to 7.5$)$ & 5.1 (3.2 to 8.0$)$ & 6.1 (4.2 to 8.7$)$ \\
\hline 2017 & $5.6(4.2$ to 7.4$)$ & 5.1 (3.2 to 7.9$)$ & 6.0 (4.1 to 8.6$)$ \\
\hline 2019 & 3.5 (2.4 to 5.0 ) & 4.1 (2.5 to 6.7 ) & 3.0 (1.8 to 5.1$)$ \\
\hline
\end{tabular}

\section{Sport facilities}

All respondents

\begin{tabular}{|c|c|c|c|}
\hline 2009 & 20.0 (17.7 to 22.6 ) & 24.3 (20.6 to 28.3 ) & 16.2 (13.3 to 19.6$)$ \\
\hline 2011 & 7.7 (6.2 to 9.5) & 9.0 (6.7 to 11.9$)$ & 6.5 (4.7 to 8.9$)$ \\
\hline 2013 & 5.3 (4.1 to 6.9 ) & 8.2 (6.0 to 11.0$)$ & 2.7 (1.6 to 4.4$)$ \\
\hline 2015 & 6.9 (5.5 to 8.6$)$ & 7.5 (5.5 to 10.2$)$ & 6.3 (4.5 to 8.7 ) \\
\hline 2017 & 5.6 (4.3 to 7.1$)$ & 6.2 (4.4 to 8.7 ) & 5.0 (3.4 to 7.1$)$ \\
\hline 2019 & 2.9 (2.0 to 4.1$)$ & 2.3 (1.3 to 4.0$)$ & 3.4 (2.2 to 5.3 ) \\
\hline \multicolumn{4}{|c|}{ Non-smokers } \\
\hline 2009 & 16.8 (14.2 to 19.7$)$ & 19.0 (15.0 to 23.7$)$ & 15.0 (11.9 to 18.9$)$ \\
\hline 2011 & 6.6 (5.0 to 8.7 ) & 8.9 (6.2 to 12.8$)$ & 5.0 (3.2 to 7.5$)$ \\
\hline 2013 & 4.8 (3.5 to 6.6$)$ & 7.0 (4.7 to 10.3$)$ & 3.0 (1.7 to 5.1$)$ \\
\hline 2015 & 7.5 (5.8 to 9.6 ) & 8.1 (5.6 to 11.5$)$ & 7.0 (4.9 to 9.8$)$ \\
\hline 2017 & 5.5 (4.1 to 7.3$)$ & 5.9 (3.9 to 8.9 ) & 5.1 (3.4 to 7.6$)$ \\
\hline 2019 & 3.5 (2.4 to 5.0 ) & 3.0 (1.7 to 5.3$)$ & 3.9 (2.5 to 6.2 ) \\
\hline \multicolumn{4}{|c|}{ Leisure facilities } \\
\hline \multicolumn{4}{|c|}{ All respondents } \\
\hline 2009 & 21.6 (19.2 to 24.3$)$ & 25.1 (21.4 to 29.2 ) & 18.5 (15.4 to 22.0 ) \\
\hline 2011 & 5.9 (4.6 to 7.5$)$ & 6.1 (4.3 to 8.6$)$ & 5.7 (4.0 to 8.0$)$ \\
\hline 2013 & 8.1 (6.6 to 9.9 ) & 9.0 (6.8 to 11.9$)$ & 7.2 (5.3 to 9.8$)$ \\
\hline 2015 & 6.3 (4.9 to 8.0$)$ & 6.2 (4.4 to 8.8 ) & 6.3 (4.5 to 8.7 ) \\
\hline 2017 & 6.0 (4.7 to 7.6$)$ & 6.2 (4.4 to 8.7$)$ & 5.7 (4.1 to 8.0 ) \\
\hline 2019 & 3.1 (2.2 to 4.3 ) & 3.9 (2.5 to 6.1$)$ & 2.3 (1.3 to 3.9 ) \\
\hline \multicolumn{4}{|c|}{ Non-smokers } \\
\hline 2009 & 19.2 (16.4 to 22.2 ) & 23.2 (18.8 to 28.2 ) & 16.0 (12.8 to 20.0$)$ \\
\hline 2011 & 5.8 (4.3 to 7.8$)$ & 6.9 (4.5 to 10.4$)$ & 5.0 (3.2 to 7.5$)$ \\
\hline 2013 & 7.9 (6.2 to 10.1$)$ & 9.1 (6.5 to 12.7$)$ & 6.9 (4.8 to 9.8$)$ \\
\hline
\end{tabular}


Table 4 Continued

\begin{tabular}{|c|c|c|c|}
\hline Year & Overall & Males & Females \\
\hline 2015 & 6.4 (4.9 to 8.4$)$ & 6.9 (4.7 to 10.2$)$ & 6.1 (4.2 to 8.7$)$ \\
\hline 2017 & 6.0 (4.5 to 7.8$)$ & 5.9 (3.9 to 8.9$)$ & 6.0 (4.1 to 8.6$)$ \\
\hline 2019 & 3.4 (2.3 to 4.9$)$ & 4.9 (3.1 to 7.6$)$ & 2.1 (1.1 to 3.9 ) \\
\hline \multicolumn{4}{|c|}{ Play areas for children } \\
\hline \multicolumn{4}{|c|}{ All respondents } \\
\hline 2009 & 13.4 (11.4 to 15.6$)$ & $13.2(10.5$ to 16.5$)$ & 13.5 (10.9 to 16.7$)$ \\
\hline 2011 & 6.4 (5.0 to 8.1$)$ & 5.9 (4.1 to 8.3$)$ & 6.8 (5.0 to 9.3$)$ \\
\hline 2013 & $6.0(4.7$ to 7.6$)$ & 3.6 (2.2 to 5.6$)$ & $8.2(6.1$ to 10.9$)$ \\
\hline 2015 & 4.2 (3.1 to 5.6$)$ & 2.9 (1.7 to 4.8$)$ & 5.4 (3.7 to 7.6$)$ \\
\hline 2017 & 5.1 (3.9 to 6.6$)$ & 4.0 (2.6 to 6.1$)$ & 6.1 (4.4 to 8.4$)$ \\
\hline 2019 & 2.1 (1.4 to 3.2$)$ & 1.0 (0.4 to 2.4$)$ & 3.0 (1.9 to 4.9$)$ \\
\hline \multicolumn{4}{|c|}{ Non-smokers } \\
\hline 2009 & $11.1(9.0$ to 13.7$)$ & $10.0(7.1$ to 13.8$)$ & $12.0(9.2$ to 15.6$)$ \\
\hline 2011 & $5.8(4.3$ to 7.8$)$ & 6.9 (4.5 to 10.4$)$ & 5.0 (3.2 to 7.5$)$ \\
\hline 2013 & 5.7 (4.3 to 7.7$)$ & 3.0 (1.7 to 5.5$)$ & $7.9(5.7$ to 11.0$)$ \\
\hline 2015 & 4.2 (3.0 to 5.9$)$ & 3.0 (1.6 to 5.4$)$ & 5.1 (3.4 to 7.6$)$ \\
\hline 2017 & 5.1 (3.7 to 6.8$)$ & 3.9 (2.4 to 6.5$)$ & 6.0 (4.1 to 8.6$)$ \\
\hline 2019 & 2.1 (1.3 to 3.4 ) & 1.1 (0.4 to 2.8 ) & 3.0 (1.8 to 5.1$)$ \\
\hline
\end{tabular}

Certainly, the reduction in SHS smoke exposure has occurred in a context of changing smoking behaviour. Since 2009, the prevalence of adult smoking in Poland has dropped by $30 \%$, to a current low of $24.4 \% .{ }^{13}$ In this context of lowered smoking rates the smoke-free policy has enjoyed strong public support. According to the Public Opinion Research Centre, a majority of the public $(74 \%)$ supported the introduction of an extensive public smoking prohibition in $2010 .^{21}$ Public support for the smoke-free policy continued to strengthen in subsequent years, increasing from $82 \%$ in 2011 to $90 \%$ in $2019 .{ }^{21}$ Nonetheless, support for smoking prohibitions may not be distributed evenly, and there may be differences in the social acceptability of indoor smoking across different types of public venues. The adoption of a smoke-free policy in Poland appears to be concordant with lowered social acceptability of smoking in workplace, public facilities as well as in culture and recreation establishments. ${ }^{21}$ However, it is possible that smoking is tolerated to a greater degree in other types of venues where higher prevalence of SHS exposure is reported, such as public transport stops and certain food and hospitality establishments. Reasons for being present at certain venues, such as transport stops, may encourage different social behaviours and perpetuate different normative behaviours compared with the other public places analysed in this study. While the Polish smoke-free policy may have benefited from strong social support together with dedicated efforts to guide implementation with the designation of a public institution responsible for monitoring the implementation of smoke-free law, further dedicated efforts may be required to address unique problems in implementation in settings where smoking behaviour continues to be more socially acceptable.

This study has several limitations. First, SHS exposure was defined based on self-report, which may invoke error such as demand bias or recall bias. Moreover, there may be people who are being exposed and are unaware of SHS exposure. Ideally, SHS exposure should be biochemically verified using biomarkers of exposures such as cotinine. ${ }^{28}$ However, in the case of interviewer-administered questionnaire surveys, selfreported SHS exposure is considered a valid measure. ${ }^{15}$ Second, questions on SHS exposure were addressed to all participants, regardless of their physical presence at each of the venue types providing exposure estimates at the whole population level, rather than by subgroups of those who attend specific venues. It is likely that SHS exposure rates by specific venues types would be higher if we were able to exclude those who had not attended each specific venue type from prevalence estimates. Nevertheless, to maintain methodological consistency, the question of SHS exposure in public places has not changed since 2009, and the data used in this study are from the only nationally representative survey on Polish tobacco use that is available. Third, all six cross-sectional surveys assessed SHS exposure in individuals aged 15 years of age and older. Therefore, rates of SHS exposure among paediatric populations may be different to those reported here. Despite these limitations, this is 
the first study from CEE region to report changes in SHS exposure across 10 years of observation. Continued measures of SHS exposure, including verification of SHS exposure based on biochemical markers, and assessment of exposure among children, are needed. Moreover, the potential impact of media campaigns, changes in smoking behaviour in private homes, ${ }^{29}$ and the lowered social acceptability of smoking should be assessed in connection with self-reported SHS exposure in future surveys.

In conclusion, this study demonstrated the success of a smoke-free law in Poland. Policy implementation approaches, including (1) categorisation of public venues by type; (2) adoption of compulsory signage of smoke-free places and (3) the establishment of an institution responsible for monitoring the implementation of smoke-free policy, are factors that have likely driven success in reducing SHS exposure ina high-burden tobacco-use country. While progress has been made in implementing a smoke-free policy, more than one in ten Poles continue to be exposed to SHS in public transport stops and facilities, thus highlighting a target of future smoke-free implementation improvement. Education programmes warning about the health risks of SHS exposure have been underutilised and may help to further shape social norms and drive change in smoking behaviour. Different approaches to smoke-free policy implementation may be needed in different types of public places (especially transport services and food or hospitality establishments). Smoke-free laws must continue to be refined, in terms of their legal boundaries as well as implementation approaches. Iterative refinement in policy adoption and implementation will help to ensure not only that all Polish venues are free of SHS, but also those in other CEE countries, ensuring universal protection from SHS exposure across the region.

\section{Author affiliations}

${ }^{1}$ School of Public Health, Centre of Postgraduate Medical Education, Warsaw, Poland ${ }^{2}$ Center for Global Tobacco Control, Department of Social and Behavioral Sciences, Harvard T.H. Chan School of Public Health, Boston, Massachusetts, United States ${ }^{3}$ Department of Hygiene and Epidemiology, Medical University of Lodz, Lodz, Poland ${ }^{4}$ Department of the Prevention of Environmental Hazards and Allergology, Medical University of Warsaw, Warsaw, Poland

\section{Twitter Mateusz Jankowski @MateJankowski}

Acknowledgements MJ acknowledges support from the Polish National Agency for Academic Exchange as part of the Walczak Scholarship Programme (grant No. PPN/WAL/2019/1/00011/U/00001).

Contributors All authors (MJ, VR, WSZ, DK, MG and JP) have contributed significantly to this work, have seen the contents of the manuscript and agreed to its submission.

Funding The authors have not declared a specific grant for this research from any funding agency in the public, commercial or not-for-profit sectors.

Competing interests None declared.

Patient and public involvement Patients and/or the public were not involved in the design, or conduct, or reporting, or dissemination plans of this research.

Patient consent for publication Not required.
Ethics approval All procedures involving human participants were conducted with the approval and oversight of the Ethical Review Board at the Centre of Postgraduate Medical Education, Warsaw, Poland (consent number: 51/PB/2020).

Provenance and peer review Not commissioned; externally peer reviewed.

Data availability statement Data are available on reasonable request. The dataset used to conduct the analyses is available from corresponding author on reasonable request.

Open access This is an open access article distributed in accordance with the Creative Commons Attribution Non Commercial (CC BY-NC 4.0) license, which permits others to distribute, remix, adapt, build upon this work non-commercially, and license their derivative works on different terms, provided the original work is properly cited, appropriate credit is given, any changes made indicated, and the use is non-commercial. See: http://creativecommons.org/licenses/by-nc/4.0/.

\section{ORCID iDs}

Mateusz Jankowski http://orcid.org/0000-0002-7142-5167

Wojciech Stefan Zgliczyński http://orcid.org/0000-0003-0054-4860

Mariusz Gujski http://orcid.org/0000-0002-2938-4795

\section{REFERENCES}

1 Oberg M, Jaakkola MS, Woodward A, et al. Worldwide burden of disease from exposure to second-hand smoke: a retrospective analysis of data from 192 countries. Lancet 2011;377:139-46.

2 Barnoya J, Glantz SA. Cardiovascular effects of secondhand smoke: nearly as large as smoking. Circulation 2005;111:2684-98.

3 United States Department of Health and Human Services. The health consequences of involuntary exposure to tobacco smoke: a report of the surgeon General. Washington, DC: US Govt Printing Office, 2006.

4 World Health Organization. WHO report on the global tobacco epidemic, 2009: implementing smoke-free environments. Geneva, Switzerland: World Health Organization Press, 2009.

5 European Commission. European Commission, Brussels,Smoke-free environments,, 2019. Available: https://ec.europa.eu/health/tobacco/ smoke-free_environments_en [Accessed 18 Apr 2020].

6 European Commission. European Commission, Brussels,Special Eurobarometer 458, 2017. Available: https://data.europa.eu/euodp/ en/data/dataset/S2146_87_1_458_ENG [Accessed 18 Apr 2020].

7 World Health Organization, Geneva. Tobacco, 2019. Available: https://www.who.int/news-room/fact-sheets/detail/tobacco [Accessed 11 Apr 2020].

8 World Health Organization. The current status of the tobacco epidemic in Poland. WHO regional office for Europe, Copenhagen, 2009.

9 World Health Organization, Geneva. Tobacco control in Poland, 2015. Available: https://www.who.int/tobacco/about/partners/bloomberg/ pol/en/ [Accessed 12 Apr 2020].

10 Ritchie H, Roser M. "Smoking" Published online at OurWorldlnData. org, 2013. Available: https://ourworldindata.org/smoking [Accessed 4 Aug 2020].

11 Jassem J, Przewoźniak K, Zatoński W. Tobacco control in Polandsuccesses and challenges. Transl Lung Cancer Res 2014;3:280-5.

12 ISAP. Protection of health against the effects of using tobacco and tobacco products act of 9th November 1995 (Journal of laws of 2019, position 2182, as amended). Available: http://isap.sejm.gov.pl/ DetailsServlet?id=WDU19960100055 [Accessed 22 Apr 2020].

13 Pinkas J, Kaleta D, Zgliczyński WS, et al. The prevalence of tobacco and e-cigarette use in Poland: a 2019 nationwide cross-sectional survey. Int J Environ Res Public Health 2019;16:E4820.

14 Central Statistical Office, Warsaw. National register of the territorial division of the country, 2019. Available: http://eteryt.stat.gov.pl/ eTeryt/english.aspx [Accessed 10 Apr 2020].

15 World Health Organization, Geneva. Tobacco free initiative, global adult tobacco survey (GATS), 2019. Available: http://www.who.int/ tobacco/surveillance/survey/gats/en/index.htm [Accessed $19 \mathrm{Apr}$ 2020].

16 Tsai J, Homa DM, Gentzke AS, et al. Exposure to Secondhand smoke among nonsmokers - United States, 1988-2014. MMWR Morb Mortal Wkly Rep 2018;67:1342-6.

17 King BA, Mirza SA, Babb SD, et al. A cross-country comparison of secondhand smoke exposure among adults: findings from the global adult tobacco survey (GATS). Tob Control 2013;22:e5.

18 European Commission, Brussels. Special Eurobarometer 385, 2012. Available: http://ec.europa.eu/public_opinion/archives/ebs/ebs_385_ en.pdf [Accessed 18 Apr 2020]. 
19 Park H, Cho S-I, Lee C. Second hand smoke exposure in workplace by job status and occupations. Ann Occup Environ Med 2019;31:3.

20 Xiao L, Yang Y, Li Q, et al. Population-Based survey of secondhand smoke exposure in China. Biomed Environ Sci 2010;23:430-6.

21 Centre for Public Opinion Research, Warsaw. Cigarette smoking, 2019. Available: https://cbos.pl/SPISKOM.POL/2019/K_104_19.PDF [Accessed 18 Apr 2020].

22 Peruga A, Hayes LS, Aguilera X, et al. Correlates of compliance with national comprehensive smoke-free laws. Tob Control 2018;27:608-13.

23 Wynne O, Guillaumier A, Twyman L, et al. Signs, Fines and compliance officers: a systematic review of strategies for enforcing smoke-free policy. Int J Environ Res Public Health 2018;15:E1386.

24 Chief Sanitary Inspectorate, Warsaw. Report on the implementation of the program for reducing the health consequences of tobacco smoking in Poland in 2010, 2011. Available: http://www2.mz.gov.pl/ wwwfiles/ma_struktura/docs/proj_sprawozdanie_2010_24052011. pdf [Accessed 18 Apr 2020].
25 Chief Sanitary Inspectorate, Warsaw. Sanitation: a country situation in 2018, 2018. Available: https://gis.gov.pl/wp-content/uploads/2019/ 09/SSK-2018-www-1.pdf [Accessed 18 Apr 2020].

26 Zeng S, Noguchi H, Shimokawa S. Partial smoking ban and Secondhand smoke exposure in Japan. Int J Environ Res Public Health 2019;16:2804.

27 Tabuchi T, Hoshino T, Nakayama T. Are partial workplace smoking bans as effective as complete smoking bans? a national populationbased study of smoke-free policy among Japanese employees. Nicotine Tob Res 2016;18:1265-73.

28 Mattes W, Yang X, Orr MS, et al. Biomarkers of tobacco smoke exposure. Adv Clin Chem 2014;67:1-45.

29 Dove MS, Dockery DW, Connolly GN. Smoke-Free air laws and secondhand smoke exposure among nonsmoking youth. Pediatrics 2010;126:80-7. 